Check for updates

Cite this: RSC Adv., 2018, 8, 41561

Received 1st November 2018

Accepted 28th November 2018

DOI: $10.1039 / c 8 r a 09048 c$

rsc.li/rsc-advances

\section{Cu-catalyzed cross-coupling reactions of vinyl epoxide with organoboron compounds: access to homoallylic alcohols $\uparrow$}

\author{
Xiao-Yu Lu, (D) *ab Jin-Song Li, ${ }^{a}$ Jin-Yu Wang, (DD ${ }^{a}$ Shi-Qun Wang, ${ }^{a}$ Yue-Ming Li, ${ }^{a}$ \\ Yu-Jing Zhu, ${ }^{a}$ Ran Zhou ${ }^{a}$ and Wen-Jing $\mathrm{Ma}^{\mathrm{a}}$
}

Copper-catalyzed cross-coupling reactions of vinyl epoxide with arylboronates to obtain aryl-substituted homoallylic alcohols are described. The reaction selectivity was different to that of previously reported vinyl epoxide ring-opening reactions using aryl nucleophiles. The reaction proceeded under mild conditions, affording aryl-substituted homoallylic alcohols with high selectivity and in good to excellent yields. The reaction provides convenient access to aryl-substituted homoallylic alcohols from vinyl epoxide

\section{Introduction}

Transition-metal-catalyzed cross-couplings are among the most valuable $\mathrm{C}-\mathrm{C}$ bond-forming reactions in modern organic synthesis. ${ }^{\mathbf{1}}$ Compared with traditional carbon-halogen or carbon- $\mathrm{OSO}_{2} \mathrm{R}$ electrophiles, ${ }^{2}$ epoxides possess ring strain that makes them susceptible to ring opening. Through ring-opening reactions of epoxides, alcohol compounds can be easily obtained with the construction of a $\mathrm{C}-\mathrm{C}$ bond. ${ }^{3}$ In recent years, various epoxide ring-opening reactions have been reported, including transition-metal-catalyzed Kumada and Negishi-type ring-opening/cross-coupling reactions of epoxides. ${ }^{4}$ Organoboron compounds have excellent stability and are commercially available. Therefore, many groups have reported Suzuki-type ring-opening/coupling reactions of epoxides. ${ }^{5}$ Furthermore, reductive ring-opening/coupling reactions and Heck-type reactions of epoxides have recently been reported. ${ }^{6}$

Vinyl epoxide is a special type of epoxide with rich chemical reactivity. The chemistry of vinyl epoxides is uniquely characterized by the conjugated reactivity of the epoxide and carboncarbon double bond. Vinyl epoxides are easily prepared using simple synthetic routes and are important building blocks with vast potential in organic synthesis. ${ }^{7}$ Owing to its unique structural features, vinyl epoxide is prone to $\mathrm{S}_{\mathrm{N}} 2^{\prime}$-type ring-opening/ coupling reactions with aryl nucleophiles, affording alcohols containing a $\mathrm{C}=\mathrm{C}$ bond. Some research groups have reported ring-opening/coupling reactions of vinyl epoxide with various types of aryl nucleophiles, including aryl bismuth compounds, ${ }^{\mathbf{8}}$

${ }^{a}$ College of Materials and Chemical Engineering, Chuzhou University, Hui Feng Road 1, Chuzhou 23900o, P. R. China

${ }^{b}$ School of Chemistry and Chemical Engineering, AnHui University, Hefei, 230601, China.E-mail:xiaoyulu@mail.ustc.edu.cn

$\dagger$ Electronic supplementary information (ESI) available. See DOI: $10.1039 / \mathrm{c} 8 \mathrm{ra} 09048 \mathrm{c}$ aryl Grignard reagents, ${ }^{9}$ aryl boron compounds, ${ }^{\mathbf{1 0}}$ aryl siloxane reagents, ${ }^{11}$ and organotin compounds (Scheme 1a). However, these previously reported works all afford aryl-substituted allylic alcohols. Exploring new chemical reaction selectivity is an interesting and challenging area of organic synthesis.

Based on previous work on Cu-catalyzed ring-opening reactions of epoxides with organoboron, ${ }^{5 c}$ we now report the first example of the Cu-catalyzed ring-opening/cross-coupling of vinyl epoxides with arylboronates, which afforded arylsubstituted homoallylic alcohols (Scheme 1b). The selectivity of the ring-opening reaction was different to that observed previously for ring-opening reactions of vinyl epoxide with aryl nucleophiles. This methodology provides access to synthetically valuable aryl-substituted homoallylic alcohols from vinyl epoxides, which are valuable structural fragments in organic synthesis.

\section{Experimental}

We began our study by selecting $m$-methoxy phenylboronate (1a) and 3,4-epoxy-1-butene (2a) as model reaction substrates (Table 1). We first examined previously reported catalytic

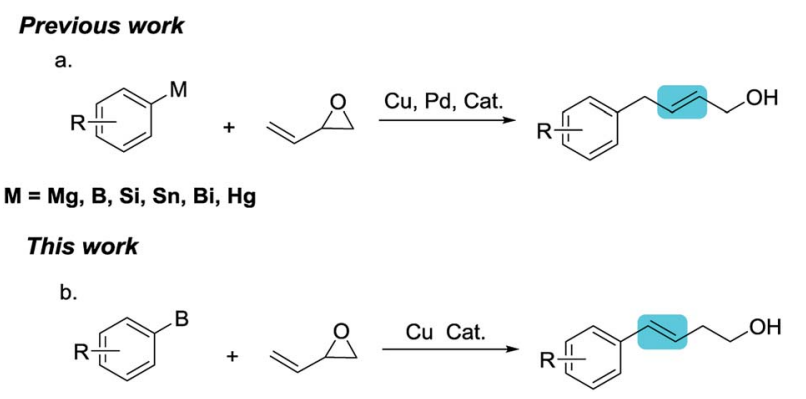

Scheme 1 Cross-couplings reactions of vinyl epoxide with aryl vucleophiles. 
Table 1 Optimization of the reaction conditions

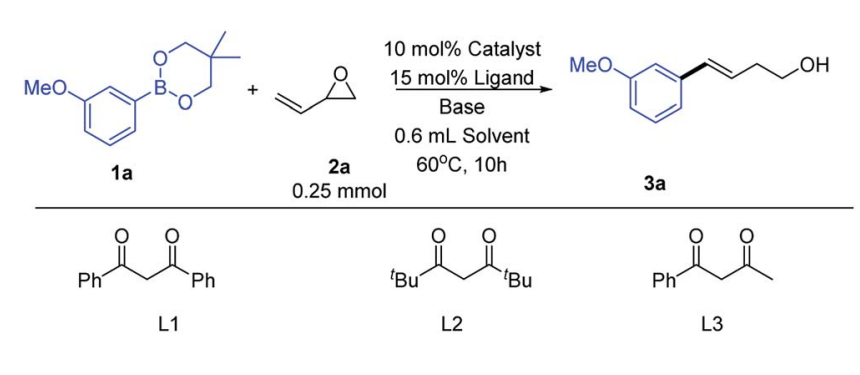

\begin{tabular}{|c|c|c|c|c|c|}
\hline Entry & Catalyst & Ligand & Base & Solvent & Yield $^{a} \%$ \\
\hline 1 & $\mathrm{CuI}$ & L1 & $\mathrm{LiO}^{t} \mathrm{Bu}$ & DMF & 21 \\
\hline 2 & $\mathrm{CuI}$ & $\mathrm{L} 2$ & $\mathrm{LiO}^{t} \mathrm{Bu}$ & DMF & 18 \\
\hline 3 & $\mathrm{CuI}$ & L3 & $\mathrm{LiO}^{t} \mathrm{Bu}$ & DMF & 12 \\
\hline 4 & $\mathrm{CuI}$ & $\mathrm{PPh}_{3}$ & $\mathrm{LiO}^{t} \mathrm{Bu}$ & DMF & 15 \\
\hline 5 & $\mathrm{CuI}$ & Xantphos & $\mathrm{LiO}^{t} \mathrm{Bu}$ & $\mathrm{DMF}$ & 41 \\
\hline 6 & $\mathrm{CuI}$ & TMEDA & $\mathrm{LiO}^{t} \mathrm{Bu}$ & DMF & 52 \\
\hline 7 & $\mathrm{CuCl}$ & Xantphos & $\mathrm{LiO}^{t} \mathrm{Bu}$ & $\mathrm{DMF}$ & 63 \\
\hline 8 & CuCl & TMEDA & $\mathrm{LiO}^{t} \mathrm{Bu}$ & DMF & 89 \\
\hline 9 & $\mathrm{CuCl}$ & TMEDA & $\mathrm{LiO}^{t} \mathrm{Bu}$ & THF & Trace \\
\hline 10 & $\mathrm{CuCl}$ & TMEDA & $\mathrm{LiO}^{t} \mathrm{Bu}$ & Dioxane & Trace \\
\hline 11 & $\mathrm{CuCl}$ & TMEDA & LiOMe & DMF & Trace \\
\hline $12^{b}$ & - & TMEDA & $\mathrm{LiO}^{t} \mathrm{Bu}$ & DMF & 0 \\
\hline
\end{tabular}

${ }^{a}$ Reaction conditions: catalyst ( $\left.10 \mathrm{~mol} \%\right)$, base (2.5 equiv.), ligand $(15 \mathrm{~mol} \%)$ in $0.6 \mathrm{~mL}$ solvent at $60{ }^{\circ} \mathrm{C}$ for $10 \mathrm{~h}$ under $\mathrm{Ar}$ atmosphere. ${ }^{b}$ No CuCl. Saturated $\mathrm{NH}_{4} \mathrm{Cl}$ was added after the reaction. The yield was determined by GC using benzophenone as internal standard (average of two GC runs).

conditions for similar Cu-catalyzed ring-opening reactions of epoxides with organoboron compounds. ${ }^{5 c, 12}$ The product was observed, but in low yield (entry 1). Therefore, the previously reported conditions were not suitable for the ring-opening cross-coupling of vinyl epoxide. To assess the roles of diketone, nitrogen, and phosphine ligands, CuI was next evaluated as a copper source (entries 2-6). Using other diketone ligands afforded a lower yield (entries 2 and 3). Using phosphine (entries 4 and 5) and nitrogen (entry 6) ligands instead of diketone ligands increased the reaction yield, but still only obtained a moderate yield. Next, we explored the effect of copper sources on the reaction efficiency (entries 7 and 8). Under the same conditions, using $\mathrm{CuCl}$ instead of $\mathrm{CuI}$ significantly increased the reaction yield (entries 7 and $8 v s$. entries 5 and 6). Pleasingly, using $\mathrm{CuCl}$ as the copper source resulted in good yields (89\% GC yield and $85 \%$ isolated yield, entry 8 ). This might be due to strongly nucleophilic iodide ions affecting the reaction. In ether solvents, hardly any product was obtained (entries 9 and 10). Similarly, almost no product was obtained when using LiOMe as base (entry 11). In the absence of a copper source, no product formation was observed (entry 12).

With optimized conditions in hand, we next examined the substrate scope (Table 2). To obtain aryl-substituted homoallylic alcohols, it was necessary to add saturated $\mathrm{NH}_{4} \mathrm{Cl}$ after the reaction was complete. Both electron-rich and electron-poor arylboronates afforded good product yields. A series of relevant functional groups, including ether (3a), halogen ( $3 \mathbf{b}$ and $3 \mathbf{c}$ ), trifluoromethoxy (3d), cyano (3e), and trifluoromethyl (3f)
Table 2 Scope of the reaction ${ }^{a}$

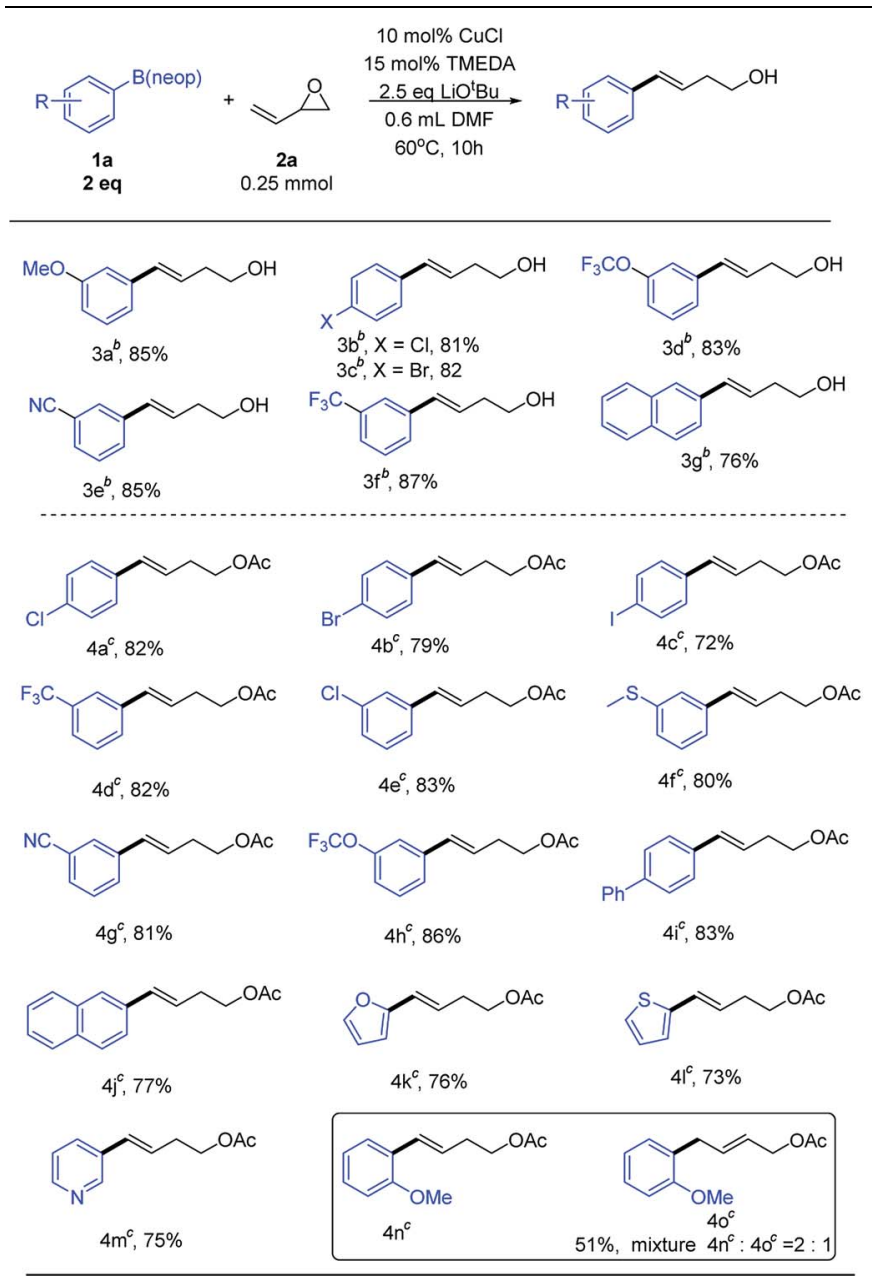

${ }^{a}$ Reaction conditions: vinyl Epoxides $(0.25 \mathrm{mmol})$, arylboronic esters (2 equiv.), $\mathrm{LiO}^{t} \mathrm{Bu}$ (2.5 equiv.). ${ }^{b}$ Saturated $\mathrm{NH}_{4} \mathrm{Cl}$ was added after the reaction was completed. ${ }^{c} 1-2 \mathrm{~mL}$ EtOAc was added after the reaction was completed, then stirred at room temperature for 1-4 h.

groups, were well tolerated, affording good yields. Notably, aryl halides, including aryl chloride and aryl bromide ( $\mathbf{3 b}$ and $\mathbf{3 c}$ ), did not hinder the transformation. Therefore, it was possible to perform subsequent cross-coupling reactions at the halogenated positions. A substrate bearing a bicyclic naphthyl group (3g) also participated in the reaction. Unfortunately, alkenylboronate did not participate in the reaction.

Free hydroxyl groups are relatively active functional groups. In many reactions, it is necessary to protect the hydroxyl groups. Hydroxyl groups can be protected with acetyl groups, which requires the use of acetyl chloride or acetic anhydride reagents. Use of these reagents is disadvantageous owing to certain hazards, such as severe irritation and corrosion. After the reaction was completed, then added 1-2 mL EtOAc and stirred at room temperature for 1-4 hour, we obtained acetyl-protected homoallylic (Table 2). Aryl halides, including aryl chloride and aryl bromide (4a and $\mathbf{4 b}$ ) were also tolerated in this reaction. Notably, the higher activity of aryl iodide (4c) did not affect the 


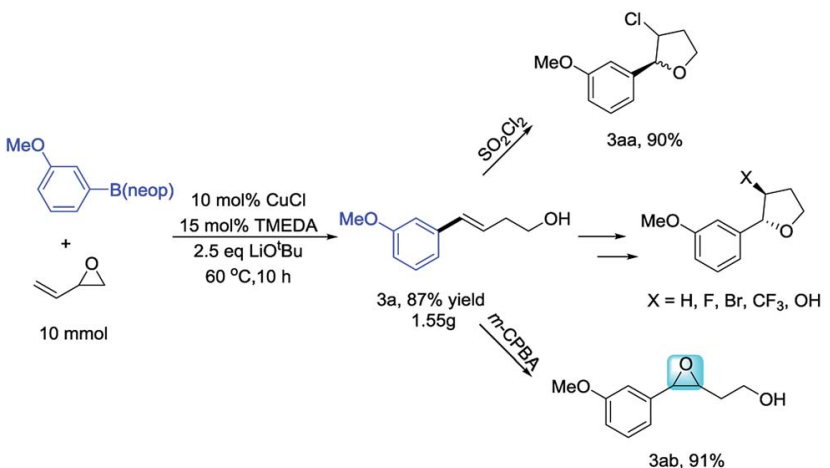

Scheme 2 Synthesis of homoallylic alcohbbols via ring opening reaction.

transformation. Both electron-rich and electron-poor substrates afforded good yields of acetyl-protected products. A series of relevant functional groups, including trifluoromethyl (4d), halogen (4e), trifluoromethoxy (4h), and cyano (4g) groups, were well tolerated, affording good yields. Arylboronate bearing a sulfur atom (4f) also participated in the reaction. Other aromatic ring substrates, such as biphenyl (4i), naphthyl (4j), furan (4k), thiophene (4l), and pyridine (4m), also participated in the reaction, affording high yields. Steric hindrance at the ortho position resulted in a mixture of protected homoallylic and allylic alcohols (4n and 4o). The homoallylic alcohol compound was detected as the only product except for orthosubstituted substrate. ${ }^{13}$

To demonstrate the scalability of this method for homoallylic alcohol preparation, we performed the Cu-catalyzed opening-ring reaction of vinyl epoxide on a gram scale, obtaining 3a in $87 \%$ yield (Scheme 2). Aryl-substituted homoallylic alcohols are an important organic synthesis fragment, and can be easily converted into $\beta$-chlorotetrahydrofurans (3aa). Under chiral catalysis, they can also be converted into chiral $\beta$ chlorotetrahydrofurans. ${ }^{14}$ Furthermore, homoallylic alcohols can also be oxidized by $m$-CPBA to 3,4-epoxyalcohols (3ab). 3,4Epoxyalcohols are important organic synthons that can participate in many reactions. ${ }^{15}$ In addition to these transformations, aryl-substituted homoallylic alcohols can also be converted into $\beta$-bromotetrahydrofuran, $\beta$-fluorotetrahydrofuran, and $\beta$-trifluoromethyl tetrahydrofuran. ${ }^{16}$ Previously, aryl-substituted homoallylic alcohols were generally synthesized through Wittig or alkene metathesis reactions. The Wittig reaction involves a long reaction route, relatively harsh conditions, and requires the use of strong bases. Meanwhile, the reaction can be

Table 3 Support experiments for the proposed mechanism

\begin{tabular}{llll}
\hline Entry & Conditions & RSM of 5a & Yield of $\mathbf{5 b}$ \\
\hline 1 & - & $>99 \%$ & 0 \\
2 & $10 \%$ CuCl & $>99 \%$ & 0 \\
3 & $15 \%$ TMEDA & $>99 \%$ & 0 \\
4 & 2.5 equiv. LiO $^{\boldsymbol{t}} \mathbf{B u}$ & trace & $>\mathbf{9 5} \%$ \\
5 & 2.5 equvi. $\mathrm{LiCl}$ & $100 \%$ & 0
\end{tabular}

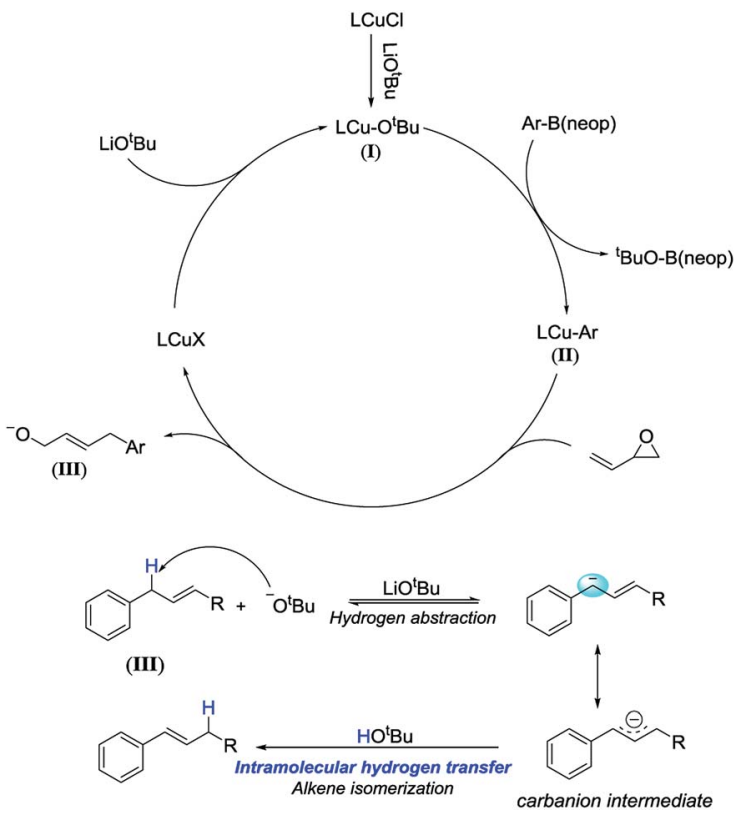

Scheme 3 Proposed catalytic cycle.

controlled at low temperature (see, ESI $\dagger$ ). ${ }^{17}$ For alkene metathesis, Grubbs catalyst is expensive, while commercial styrene is relatively less (see ESI $\dagger$ ). ${ }^{18}$ The Heck reaction of aryl halides with 3-buten-1-ol, generally affords 4-arylbutanal as the major product (see ESI $\dagger$ ). ${ }^{19}$ Therefore, to synthesize aryl-substituted homoallylic alcohols, the metal-catalyzed Sonogashira reaction of aryl halides with but-3-yn-1-ol is necessary, followed by alkyne reduction. ${ }^{20}$ These alternative methods clearly show that the reaction reported herein provides an efficient, economical, and convenient method for the synthesis of aryl-substituted homoallylic alcohols.

To illustrate the reaction mechanism, we performed a series of reactions using (E)-4-phenylbut-2-en-1-ol (Table 3, eqn (1)). The isomerization product could not be obtained without adding reagents (entry 1). Adding $10 \mathrm{~mol} \% \mathrm{CuCl}$ or $15 \mathrm{~mol} \%$ TMEDA also did not afford any isomerized product (entries 2 and 3). When 2.5 equiv. of $\mathrm{LiO}^{t} \mathrm{Bu}$ was added, the isomerization product was obtained in high yield and no residual material was detected (entry 4 ). In contrast, adding 2.5 equiv. of LiCl did not afford any isomerization products (entry 5 ). This confirmed that lithium ions did not cause isomerization. Similarly, the $\mathrm{LiO}^{t} \mathrm{Bu}$ can also promote the alkene isomerization of allylbenzene (eqn (2)). It is confirmed by these experiments that the $\mathrm{LiO}^{t} \mathrm{Bu}$ is the cause of the alkene migration. Previous studies have indicated that the base, such as $\mathrm{K}_{3} \mathrm{PO}_{4}, \mathrm{KF}, \mathrm{KOH}, \mathrm{NaO}^{t} \mathrm{Bu}, \mathrm{KO}^{t} \mathrm{Bu},{ }^{21}$ can promote the alkene isomerization of allylbenzene. Researchers have confirmed that the isomerization goes through an intramolecular base-promoted hydrogen transfer process (carbanion intermediate). ${ }^{\mathbf{2 1 a}, \mathbf{2 1 e}}$ From these experiments, we proposed a possible catalytic cycle (Scheme 3 ). The copper salt first reacts with $\mathrm{LiO}^{t} \mathrm{Bu}$, generating $\mathrm{LCu}-\mathrm{O}^{t} \mathrm{Bu}(\mathbf{I})$. Transmetalation then produces $\mathrm{LCu}-\mathrm{Ar}(\mathrm{II})$, which reacts with vinyl epoxide via an $\mathrm{S}_{\mathrm{N}} 2^{\prime}$ type ring-opening/coupling to afford intermediate (III). 
Intermediate III then undergoes intramolecular hydrogen transfer and alkene isomerization to afford the aryl-substituted homoallylic alcohols.

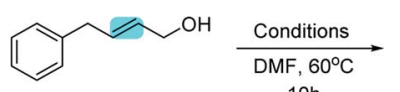

$5 a$

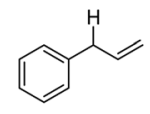

$6 a$

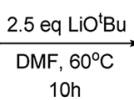

$10 \mathrm{~h}$

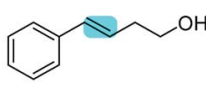

$5 b$

$6 b,>90 \%$ yield

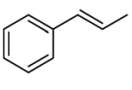

\section{Conclusions}

In summary, we have developed the first Cu-catalyzed ringopening reaction of vinyl epoxides with arylboronates. This reaction affords $(E)$-aryl-substituted homoallylic alcohols. The reaction selectivity was different to that of previous ringopening reactions of vinyl epoxide with aryl nucleophiles. This reaction provides an effective method for the synthesis of aryl-substituted homoallylic alcohols, which are valuable synthetic intermediates in modern organic synthesis. The mild reaction conditions tolerate a wide variety of functional groups.

\section{Conflicts of interest}

There are no conflicts to declare.

\section{Acknowledgements}

This work was supported by 2017qd11, 2016GH15, and Anhui Province Major Special Projects (16030801108).

\section{Notes and references}

1 F. Diederich and P. J. Stang, Metal-Catalyzed Cross-Coupling Reactions, Wiley-VCH, Weinheim, 1998.

2 (a) R. Jana, T. P. Pathak and M. S. Sigman, Chem. Rev., 2011, 111, 1417; (b) S. Z. Tasker, E. A. Standley and T. F. Jamison, Nature, 2014, 509, 299; (c) A. Suzuki, Angew. Chem., Int. Ed., 2011, 50, 6722; (d) X. Y. Lu, M. L. Hong, H. P. Zhou, Y. Wang, J. Y. Wang and X. T. Ge, Chem. Commun., 2018, 54, 4417; (e) X. Y. Lu, J. H. Liu, X. Lu, Z. Q. Zhang, T. J. Gong, B. Xiao and Y. Fu, Chem. Commun., 2016, 52, 5324; (f) X.-Y. Lu, J.-S. Li, M.-L. Hong, J.-Y. Wang and W.-J. Ma, Tetrahedron, 2018, 74, 6979.

3 (a) P. Crotti and M. Pineschi, in Aziridines and Epoxides in Organic Synthesis, Wiley-VCH Verlag GmbH \& Co. KGaA, 2006, pp. 271-313; (b) V. V. Fokin and P. Wu, in Aziridines and Epoxides in Organic Synthesis, Wiley-VCH Verlag $\mathrm{GmbH}$ \& Co. KGaA, 2006, pp. 443-477; (c) P. A. S. Lowden, in Aziridines and Epoxides in Organic Synthesis, Wiley-VCH Verlag GmbH \& Co. KGaA, 2006, pp. 399-442; (d) H. Ohno, in Aziridines and Epoxides in Organic Synthesis, Wiley-VCH
Verlag GmbH \& Co. KGaA, 2006, pp. 37-71; (e) B. Olofsson and P. Somfai, in Aziridines and Epoxides in Organic Synthesis, Wiley-VCH Verlag GmbH \& Co. KGaA, 2006, pp. 315-347; (f) C.-Y. Huang and A. G. Doyle, Chem. Rev., 2014, 114, 8153.

4 (a) M. Alam, C. Wise, C. A. Baxter, E. Cleator and A. Walkinshaw, Org. Process Res. Dev., 2012, 16, 435; (b) C. Bonini, L. Chiummiento, M. T. Lopardo, M. Pullez, F. Colobert and G. Solladié, Tetrahedron Lett., 2003, 44, 2695; (c) C. Y. Huang and A. G. Doyle, J. Am. Chem. Soc., 2012, 134, 9541; (d) K. L. Jensen, E. A. Standley and T. F. Jamison, J. Am. Chem. Soc., 2014, 136, 11145; (e) D. K. Nielsen, C. Y. Huang and A. G. Doyle, J. Am. Chem. Soc., 2013, 135, 13605.

5 (a) M. L. Duda and F. E. Michael, J. Am. Chem. Soc., 2013, 135, 18347; (b) Y. Takeda, Y. Ikeda, A. Kuroda, S. Tanaka and S. Minakata, J. Am. Chem. Soc., 2014, 136, 8544; (c) X. Y. Lu, C. T. Yang, J. H. Liu, Z. Q. Zhang, X. Lu, X. Lou, B. Xiao and Y. Fu, Chem. Commun., 2015, 51, 2388.

6 (a) Y. Zhao and D. J. Weix, J. Am. Chem. Soc., 2013, 136, 48; (b) Y. Zhao and D. J. Weix, J. Am. Chem. Soc., 2015, 137, 3237; (c) S. Teng, M. E. Tessensohn, R. D. Webster and J. S. Zhou, ACS Catal., 2018, 8, 7439.

7 J. He, J. Ling and P. Chiu, Chem. Rev., 2014, 114, 8037.

8 S.-K. Kang, H.-C. Ryu, Y.-T. Hong, M.-S. Kim, S.-W. Lee and J.-H. Jung, Synth. Commun., 2001, 31, 2365.

9 Z. Zhao, G. L. Araldi, Y. Xiao, A. P. Reddy, Y. Liao, S. Karra, N. Brugger, D. Fischer and E. Palmer, Bioorg. Med. Chem. Lett., 2007, 17, 6572.

10 (a) J. Kjellgren, J. Aydin, O. A. Wallner, I. V. Saltanova and K. J. Szabó, Chem.-Eur. J., 2005, 11, 5260; (b) J. P. Patterson, P. Cotanda, E. G. Kelley, A. O. Moughton, A. Lu, T. H. Epps 3rd and R. K. O'Reilly, Polym. Chem., 2013, 4, 2033; (c) G. W. Roffe, G. J. Tizzard, S. J. Coles, H. Cox and J. Spencer, Org. Chem. Front., 2016, 3, 957.

11 J. R. Herron, V. Russo, E. J. Valente and Z. T. Ball, Chem.-Eur. J., 2009, 15, 8713.

12 (a) C. T. Yang, Z. Q. Zhang, Y. C. Liu and L. Liu, Angew. Chem., Int. Ed., 2011, 50, 3904; (b) G. Z. Wang, J. Jiang, X. S. Bu, J. J. Dai, J. Xu, Y. Fu and H. J. Xu, Org. Lett., 2015, 17, 3682; (c) Z. Q. Zhang, C. T. Yang, L. J. Liang, B. Xiao, X. Lu, J. H. Liu, Y. Y. Sun, T. B. Marder and Y. Fu, Org. Lett., 2014, 16, 6342; (d) Z. Q. Zhang, B. Zhang, X. Lu, J. H. Liu, X. Y. Lu, B. Xiao and Y. Fu, Org. Lett., 2016, 18, 952; (e) Y. Y. Sun, J. Yi, X. Lu, Z. Q. Zhang, B. Xiao and Y. Fu, Chem. Commun., 2014, 50, 11060.

13 (a) L. A. Batory, C. E. McInnis and J. T. Njardarson, J. Am. Chem. Soc., 2006, 128, 16054; (b) M. Brichacek, L. A. Batory and J. T. Njardarson, Angew. Chem., Int. Ed., 2010, 49, 1648.

14 (a) X. Zeng, C. Miao, S. Wang, C. Xia and W. Sun, Chem. Commun., 2013, 49, 2418; (b) W. Sun, X. Zeng, C. Miao, S. Wang and C. Xia, Synthesis, 2013, 45, 2391.

15 (a) A. Banerjee and H. Yamamoto, Org. Lett., 2017, 19, 4363; (b) C. Wang and H. Yamamoto, J. Am. Chem. Soc., 2014, 136, 1222; (c) Y. Q. Zhang, N. Funken, P. Winterscheid and A. Gansauer, Angew. Chem., Int. Ed., 2015, 54, 6931. 
16 (a) R. Lin, H. Sun, C. Yang, Y. Yang, X. Zhao and W. Xia, Beilstein J. Org. Chem., 2015, 11, 31; (b) Y. Wang, M. Jiang and J.-T. Liu, Adv. Synth. Catal., 2016, 358, 1322.

17 (a) B. J. Stokes, S. M. Opra and M. S. Sigman, J. Am. Chem. Soc., 2012, 134, 11408; (b) A. M. Del Hoyo, A. G. Herraiz and M. G. Suero, Angew. Chem., Int. Ed., 2017, 56, 1610.

18 P. R. Walker, C. D. Campbell, A. Suleman, G. Carr and E. A. Anderson, Angew. Chem., Int. Ed., 2013, 52, 9139.

19 M. van Gemmeren, M. Borjesson, A. Tortajada, S. Z. Sun, K. Okura and R. Martin, Angew. Chem., Int. Ed., 2017, 56, 6558.
20 (a) X. Su, Y. Sun, J. Yao, H. Chen and C. Chen, Chem. Commun., 2016, 52, 4537; (b) J. Tummatorn, S. Ruchirawat and P. Ploypradith, Chem.-Eur. J., 2010, 16, 1445.

21 (a) D. J. Cram and R. T. Uyeda, J. Am. Chem. Soc., 1962, 84, 4358; (b) R. Neumann and Y. Sasson, J. Mol. Catal., 1985, 33, 201; (c) T. X. Luu, T. Lam, T. Le and F. Duus, Molecules, 2009, 14, 3411; (d) I. Al-Maskery, K. Girling, S. D. Jackson, L. Pugh and R. R. Spence, Top. Catal., 2010, 53, 1163; (e) N. Qafisheh, S. Mukhopadhyay, A. V. Joshi, Y. Sasson, G.-K. Chuah and S. Jaenicke, Ind. Eng. Chem. Res., 2007, 46, 3016. 